Cahiers $d u$ MONDE RUSSE

\section{Cahiers du monde russe}

Russie - Empire russe - Union soviétique et États indépendants

$43 / 4 \mid 2002$

Intellectuels et intelligentsia

\title{
Sergej Bogatyrev, The sovereign and his counsellors
}

Pierre GONNEAU

\section{OpenEdition \\ Journals}

Édition électronique

URL : https://journals.openedition.org/monderusse/4004

DOI : 10.4000/monderusse.4004

ISSN : $1777-5388$

Éditeur

Éditions de l'EHESS

\section{Édition imprimée}

Date de publication : 30 décembre 2002

Pagination : 680-682

ISBN : 2-7132-1796-2

ISSN : $1252-6576$

Référence électronique

Pierre GONNEAU, "Sergej Bogatyrev, The sovereign and his counsellors », Cahiers du monde russe [En ligne], 43/4 | 2002, mis en ligne le 06 juillet 2009, consulté le 03 septembre 2022. URL : http:// journals.openedition.org/monderusse/4004; DOI : https://doi.org/10.4000/monderusse.4004

Ce document a été généré automatiquement le 3 septembre 2022

Tous droits réservés 


\title{
Sergej Bogatyrev, The sovereign and his counsellors
}

\author{
Pierre GONNEAU
}

\section{RÉFÉRENCE}

Sergej BOGATYREV, The sovereign and his counsellors. Ritualised consultations in Muscovite political culture 1350s-1570s. Helsinki, Academia Scientiarum Fennica, 2000, 297 p. (Annales Academiæ scientiarum Fennicæ. Humaniora, 307)

1 L'étude de Sergej Bogatyrev, consacrée aux formes de consultation au sein de l'élite gouvernante russe, peut être vue comme un prolongement pratique du travail de Marshall Poe, comme une vérification sur le terrain, infirmant la thèse du despotisme russe. L'auteur met en effet en évidence l'existence permanente d'un processus coutumier de partage des décisions entre le souverain et plusieurs cercles, plus ou moins proches, de courtisans. Il conclut même: "L'image du conseiller-apôtre correspondait à celle du souverain, incarnation du Christ. Le souverain et le conseil constituaient donc une seule entité [...]. Sous le régime autocratique, ni le souverain ni les boyards ne jouissaient d'un monopole du pouvoir politique. Puisque l'on attribuait aux devoirs du conseiller une nature sacrale, la sphère de son activité n'était jamais distincte de celle du souverain " (p. 221). Le cœur du problème est de définir dans quelle mesure le processus du conseil débouche ou non sur un Conseil, une ou des institutions dotées d'une certaine permanence dans sa (leur) structure et dans sa (leur) composition. Une partie de la démonstration et l'étude historiographique donnée dans l'Appendice I tendent à montrer que la «Douma des boyards» est une «expression commode inventée par les historiens» (p. 253), mais qu'elle ne correspond pas à une véritable institution, à un organe fonctionnel du pouvoir central, comparable aux bureaux (prikazy) qui prennent peu à peu en charge l'administration des recettes fiscales, des ambassades, de la sûreté intérieure, des bénéfices, etc. Toutefois, Bogatyrev identifie un Conseil privé du souverain (Privy Council, en russe Bližnjaja Duma) qui se structure essentiellement pendant le règne d'Ivan le Terrible, et il analyse son rôle au sein de l'appareil d'État russe (ch. 3-4). 
«À la fin du troisième quart du Xvi e siècle, le Conseil occupait une place bien définie dans le système de l'État. Il était devenu un intermédiaire entre le souverain et les organes centraux de gouvernement, mais aussi entre le souverain et la cour [...]. Au xvi ${ }^{e}$ siècle, le Conseil privé constituait le sommet de la cour et il était fréquenté par les chefs des principales factions de la cour. En même temps, l'admission au Conseil n'était pas directement liée à la possession du rang de boyard ou de quartier-maittre - kol'ničij - à la cour» (p. 222).

Dans son développement, l'auteur a recours à plusieurs approches, souvent bienvenues, mais parfois plus juxtaposées que conjuguées: l'étude prosopographique des élites, la synthèse sur le gouvernement de l'État russe (schémas à l'appui, comme p. 164 et 209) et l'histoire des représentations mentales du gouvernement. Les sources utilisées sont fort nombreuses, mais une place plus importante est faite aux textes narratifs. Au premier rang viennent les compilations de chroniques, en particulier les manuscrits illustrés, comme la Chronique de Radziwi ( $\mathrm{xv}^{\mathrm{e}}$ siècle), récemment éditée sous forme de fac-similé, et la Chronique Enluminée (Licevoj letopisnyj svod, v.1568-1576), véritable mine iconographique dont on souhaiterait vivement voir un jour les enluminures mises à la disposition de la communauté des chercheurs ${ }^{1}$. D'autres représentations graphiques nous sont fournies par les bas-reliefs du trône impérial d'Ivan le Terrible (1551). Le parti de confronter texte et image nous semble une excellente initiative, jusqu'ici peu fréquente dans l'historiographie russe ${ }^{2}$. Les récits concernant la bataille de Kulikovo et les raids tatars contre les pays russes, souvent inclus dans les chroniques russes des $\mathrm{XV}^{\mathrm{e}}$ $\mathrm{xVI}^{\mathrm{e}}$ siècles, sont également mis à contribution, de même que certains textes hagiographiques ou polémiques. En outre, Bogatyrev analyse, avec la prudence requise, le témoignage controversé du voyageur anglais GilesFletcher. Les documents épistolaires, principalement la correspondance d'Ivan le Terrible, se situent à mi-chemin entre les œuvres édifiantes ou polémiques et les sources diplomatiques. Ces dernières ne manquent pas non plus: testaments et traités princiers, jugements, comptes rendus d'ambassades, correspondance entre les boyards moscovites et la Rada lituanienne, registres des rangs (razrjadnye knigi). La plupart des pièces utilisées ont déjà fait l'objet de publications dont la liste est donnée (p. 274-276). Toutefois, des documents d'archives inédits ont aussi été employés ( $c f$. les cotes données aux p. 30-31, 147, 153, 157, 158, 160 163165167,169 172, 174, 192, 204, 205, 212), et l'on peut regretter que l'auteur ne les présente pas de façon systématique dans le sous-chapitre consacré à ses sources (p. 26-36). Ainsi que le montre la bibliographie, il a eu recours aussi bien aux travaux parus en Russie (dont les siens, bien entendu) qu'aux importantes contributions occidentales de ces trente dernières années ${ }^{3}$. Le fait est, malheureusement, encore trop rare pour que l'on souligne ce trait positif. Sans remplacer définitivement les recherches antérieures, Bogatyrev sait à la fois s'appuyer sur elles et fournir de nouvelles pistes de recherches (l'iconographie en particulier), tout en apportant de nombreux renseignements ponctuels sur la carrière des courtisans russes. 


\section{NOTES}

1. M. V. Kukuškina, G. M. Prohorov, eds, Radzivilovskaja letopis' : tekst, issledovanija, opisanie miniatjur, Moscou, 1994, 2 vol.

2. L'une des études les plus intéressantes combinant texte et image concerne le culte du métropolite Pierre (1326), cf. R. A. Sedova, Svjatitel' Petr mitropolit moskovskij v literature i iskusstve Drevnej Rusi, Moscou, 1993.

3. Cf. G. Alef, The origins of Muscovite autocracy: the age of Ivan III, Wiebaden, 1986 (Forschungen zur Osteuropäischen Geschichte, 39) ; R. O. Crummey, Arisocrats and servitors: the Boyar elite in Russia 1613-1689, Princeton, 1977 ; E. Keenan, The Kurbskii-Groznyi apocrypha: the seventeenthcentury genesis of the "Correspondence " attributed to Prince A.M. Kurbskii and Tsar Ivan the Terrible, Cambridge, MA,1971 ; Nancy S. Kollmann, Kinship and politics: the making of the Muscovite political system 1345-1547, Stanford, 1987 ; id., "Ritual and social drama at the Muscovite Court », Slavic Review, 45, 1986, p. 486-502 ; id., "Pilgrimage, procession and symbolic space in sixteenthcentury Russian politics», in Medieval Russian culture, t. 2, Berkeley, 1994, p. 163-182; D. Rowland, "The problem of advice in Moscovite tales about the Time of Troubles ", Russian History, 6, 1979, p. 259-283 ; id., « Did Muscovite literary ideology place limits on the power of the Tsar 1540s-1660s?», Russian Review, 49, 1990, p. 125-155; id. "Biblical military imagery in the political culture of early modern Russia : the blessed host of the Heavenly Tsar ", in Medieval Russian culture, t. 2, Berkeley, 1994, p.182-212. 